\title{
A formação de cidades ribeirinhas no Araguaia a partir de presídios militares - século XIX
}

DOSSIER RIOS E CIDADES: ARAGUAIA

\section{Francisquinha Laranjeira Carvalho}

Mestre em História pela PUC-GO. Especialista em História Regional do Tocantins e em Gestão da Conservação do Patrimônio Cultural da América Latina. Goiânia [GO] Brasil <francisquinhalc@yahoo.com.br>.

\begin{abstract}
Resumo
0 presente artigo aborda o Rio Araguaia como o caminho, a estrada para o desenvolvimento do comércio, na segunda metade do século XIX. A navegação fluvial brasileira apresenta-se, nesse período, como meio de propiciar condições de vida aos moradores das cidades mais afastadas dos principais centros comerciais e próximas dos rios, fundamentadas no intercâmbio comercial mais efetivo com o exterior. Na primeira metade do século XIX, os receios de invasão externa através dos rios levaram o príncipe D. João VI, em 1809, a viabilizar a política de defesa e proteção do Território Imperial através da implantação de Presídios Militares nos principais rios brasileiros. No vasto sertão do Araguaia, essas tentativas foram frustradas em vista da não permissão dos povos indígenas - Xavantes, Caiapós, Karajás, Javaés, Xambioás e outros, que viviam agrupados em aldeias, avessos à entrada de outros povos de culturas distintas. Na segunda metade do referido século, o governo Imperial, ciente da impossibilidade de desenvolver o comércio via fluvial, optou por adotar a política de Implantação de Presídios Militares com a pretensão de criar os Portos de Embarques e Entrepostos Comerciais para garantir a navegação comercial e a formação de cidades beiras. Uma saída em duplo sentido, para possibilitar uma ligação com o litoral e salvar a Província do marasmo em que se encontrava.
\end{abstract}

\section{Palavras-chave}

Cidades ribeirinhas. Presídios. Navegação. Práticas culturais.

\section{The emergence of Araguaia's riverside cities from Military Prisons - 19th century}

\begin{abstract}
This article approaches the Araguaia River as the way, the road to the development of commerce, in the second half of the nineteenth century. In this period, Brazilian river navigation is a means of providing living conditions to the inhabitants of the cities most distant from the main shopping centers and close to the rivers, based on the most effective commercial exchange with the outside world. In the first half of the 19th century, fears of external invasion through the rivers led Prince D. João VI, in 1809, to make viable the defense and protection policy of the Imperial Territory through the establishment of Military Prisons in the main Brazilian rivers. In the vast backlands of the Araguaia, these attempts were thwarted in view of the nonpermission of the indigenous peoples - Xavantes, Caiapós, Karajás, Javaés, Xambioás and others, who lived grouped in villages, averse to the entrance of other peoples from different cultures. In the second half of the century, the Imperial government, aware of the impossibility of developing river traffic, opted to adopt the Military Prisons Implantation policy with the intention of creating the Shipping Ports and Commercial Warehouses to guarantee commercial navigation and Formation of city borders. A two-way exit, to allow a connection with the coast and save the Province from the doldrums in which it was.
\end{abstract}

\section{Keywords}

Riverfront towns. Prisons. Navigation. Cultural practices. 


\section{Introdução}

Falar do nascimento de cidades fundadas às margens de um Rio é falar de um espaço social bastante complexo. Assim, eu começo falando do poder do Rio.

0 rio é um elemento natural que tem a capacidade de superar obstáculos ou resistir às pressões externas ou adversas. 0 rio tem resiliência, tem o poder de se auto-regenerar. Ele, em parceria com o sol, a lua e as estrelas, provoca no imaginário humano, prazer, medo, encantamento, inspirações poéticas. É um espaço onde se cruzam interesses de grupos sociais e ideologias.

Gandara, tentando mostrar que o rio acumula uma boa quantidade de representações, sentiu a necessidade de abordar o questionamento do escritor alemão Hermann Hesse, descrito no romance Sidharta (1922), que busca pela plenitude espiritual:

[...] o rio tem muitas vozes, um sem número de vozes: não é meu amigo? Não te parece que tem a voz de um rei e a de um guerreiro, a voz de um touro e a de uma ave noturna, a voz de uma parturiente e de um homem que suspira, e inúmeras outras ainda? (apud Gandara, 2005, p.1789).

Gandara afirma que:

[...] os rios são construtores de mundos sociais e acumulam uma boa quantidade de repre-sentações. Diz que é o lugar onde as pessoas se abrem aos mistérios da natureza; Ao patrimônio simbólico, possibilitando a interpretação, como terreno da criação cultural, passagem de forças e encontro dos indivíduos (Gandara, 2005, p.1789).

Como todos os rios do Brasil, o Rio Araguaia tem sua própria história, a história de sua vida, que pode ser falada, lida ou cantada. Tem a história da origem de seu nome. Os índios Karajás, seus mais tradicionais usuários, agradecidos pela sua bondade o denominaram de "BerohoKã", que quer dizer 'rio grande'. Araguaia significa 'rio das araras' ou 'papagaio manso'.

O Rio Araguaia tem orgulho de ser tipicamente brasileiro, nasce na Chapada das Emas, na Serra do Caiapó, na confluência dos estados de Goiás e Mato Grosso do Sul, escorre para a planície para encontrar outro majestoso e soberano rio: o Tocantins. Formando uma grande rede da região Centro-Oeste ao Norte do País passa por regiões de clima equatorial quente e úmido, e semi-úmido. Sua extensão é de $2.115 \mathrm{~km}$, com extensão navegável de $1.818 \mathrm{~km}$ e profundidade mínima de $1.0 \mathrm{~m}, 0.9 \mathrm{~m}, 0.8 \mathrm{~m}$, respectivamente. Corre quase paralelamente ao rio Tocantins.

No seu percurso, abre seus braços de guerreiro para envolver a maior ilha fluvial do mundo, a ilha do Bananal. Esta ilha recebeu seu primeiro nome de Ilha de Sant'Ana e possui 20 mil quilômetros quadrados. Os índios Javaés a denominaram de Camonaré.

Mello afirma poeticamente que o Rio Araguaia não encontrou seu leito definitivo ainda, no seu curso médio, uma vez que busca desesperadamente, ano após anos, nas suas margens arenosas sua eterna morada. Assim, diz Mello:

O Rio Araguaia procura há milênios essa morada, para seu pouso e sua caminhada ininterrupta; um trilheiro mais cômodo, onde possa afundar um pouco a estrada, como rastro de carro de boi, ou à trilha que leva à fonte. Envaidecido investe contra barrancos de suas margens, ora de um lado, ora de outro, na incansável busca de um caminho único onde possa o navegante conhecer tintim por tintim, as pedras, tocos, galhadas, garranchos, jaibara, estirões, remansos, gorgulhos, barreiras, praias, alcantilados, furos, corredeiras, travessões e cachoeiras, sem o perigo de mudar uma ponta de toco, um emburrado que faz alagar as embarcações sem a ordem severa do inconfundível banzeiro, companheiro dileto das horas de ventania e inseparável nas cachoeiras (Mello, 2000, p. 37-38).

O rio Araguaia é rico de representações culturais. Com diferentes significados representa para os visitantes e poetas, símbolo de beleza, prazer, encantamento, mistério, inspiração, paisagem. Mas 
para as populações ribeirinhas sua representação vai muito além, gera vidas e alimenta. É o ponto de encontro entre amigos. É o elo entre o passado e presente. É o baú das histórias dos ribeirinhos. É o caminho de travessia para suas praias, torrões ou cidades. É a possibilidade e garantia de pescaria e entretenimento e muito mais.

0 rio Araguaia carrega consigo muitas histórias. História dos índios; história dos bandeirantes, história dos missionários; história da navegação, história dos viajantes e comerciantes; história dos povos ribeirinhos, que tem relações íntima e cotidianas com ele; história dos pescadores; história do nascimento de várias cidades, enfim o rio Araguaia é um capital natural rico de representações culturais.

\section{Cidades ribeirinhas e os Presídios Militares no Araguaia}

O rio Araguaia configura-se como um espaço natural que serviu de escoadouro econômico e serve de integração cultural entre regiões. Como fronteira serve, também, como divisor natural entre quatro estados: Mato Grosso, Goiás, Tocantins e Pará. As fronteiras representam muito mais que uma mera divisão e unificação dos pontos diversos. E, como fronteira natural, define culturalmente os referidos espaços territoriais através das aplicações das leis e de regulamentos específicos e que se aplicam aos seus habitantes. Ações estas, que tiveram início quando os lusitanos decidiram delimitar fronteiras para defender e guardar o imenso território brasileiro, por eles desbravado.

No século XIX, foi o principal caminho, a estrada fluida, visto como os meios possíveis de fazer aumentar e prosperar os negócios da Província de Goiás com a do Pará. Era a solução para os problemas econômicos e financeiros. Estrada líquida. Na condição de caminho, o rio trouxe os primeiros colonizadores ao vasto sertão do Araguaia. Promoveu a fundação de várias cidades em todo o seu percurso, tanto à direita, quanto á sua esquerda.

No século XIX, muitas cidades situadas às margens do rio Araguaia, nasceram com funções específicas da implantação de Presídios Militares. Foram erigidas para defender e fortalecer o comércio, tais como: Aruanã (antigo Presídio de Santa Leopoldina), Itacaiú (Presidio de Itacaiú), São Félix do Araguaia (Presídio de São Félix), Couto de Magalhães (Presídio de Santa Maria) e Araguacema (Presídio de Santa Maria do Araguaia), São João das Duas Barras (Presídio de São João). Foi tão somente ao longo do tempo que estas cidades adquiriam suas funções sociais.

O termo presídio era entendido, no século passado, como conquista de território e expansão de fronteiras, parte do processo de povoamento, defesa e especialização agrícola. Foram construídos oficialmente e sob o controle do governo. Receberam várias denominações, tais como: núcleos militares de povoamento; núcleos de colonização militar; presídios militares de povoamento; colônias militares de povoamento; fortificações lindeiras; fortificações limítrofes ou apenas fortes. Palacin e Moraes (1989), diz que os presídios fundados em Goiás até meados do século XIX, "eram colônias militares de defesa, povoamento e especialização agrícola". Os presídios ou colônias militares eram entendidos como ferramenta de defesa, conquista e expansão de fronteiras. Afirma Oliveira que [...]

[...] fundar povoações e depois erigi-las em vilas era um título de benemerência dos governadores coloniais, um serviço prestado ao rei, tão recomendável aos olhos da Metrópole e da Coroa como o serviço de povoamento dos sertões e o da civilização do gentil (Viana, 1974, p.109).

Os presídios foram, em grande parte, mantidos e desenvolvidos à custa do trabalho, principalmente dos negros e mestiços. Em muitos destes presídios, viviam gentios catequizados e pacíficos. Os campos de lavouras eram cultivados pelos negros, considerados "os desocupados", ou "os desclassificados" e por criminosos (Tiballi, 1991).

Nos estaleiros e embarcações, os colonos se serviram mais da mão de obra indígena, visto que os índios são exímios remadores e conhecedores de práticas da produção de pequenas embarcações.

Os objetivos dos presídios, fundados na segunda metade do século XIX, estão contidos no Decreto 750, de dois de janeiro de 1850. 0 Decreto foi elaborado pelo Ministério e Secretários de 
Estado e Negócios do Império, aprovado pelo Legislativo e sancionado por D. Pedro II. Através desse documento, estabeleceu-se o regulamento para as instalações de presídios às margens do Rio Araguaia.

Para que possamos compreender os fatores que levaram o governo português a construir Presídios Militares nas margens do Rio Araguaia, devemos considerar os fatores internos brasileiros e externos do período proposto, bem como as especificidades locais.

Caio Prado Jr. afirma que:

"A primeira metade do século XIX é de transição, fase de ajustamento à nova situação criada pela independência e autonomia nacional; a crise econômica, financeira, política e social que se desencadeia sobre o Brasil desde o momento da transferência da corte portuguesa em 1808, e, sobretudo da emancipação política de 1822, prolongam-se até meados do século; e se é verdade que já antes deste momento se elaboram os fatores de transformação, é somente depois dele que amadurecem e produzem todos os frutos que modificariam tão profundamente as condições do país" (Prado Jr.,1996, p. 192).

Em 1807, a Metrópole Portuguesa, por não ter aderido ao Bloqueio Continental, (guerra napoleônica (1803-1814), decretado pelo Imperador da França, Napoleão Bonaparte, encontrava-se invadida pelas tropas francesas comandadas pelo General Junot. Nesse mesmo ano a França e a Espanha pretendiam dominar Portugal e suas colônias Prado Jr. (1996, p.192).

Devido às agitações que ocorriam na Europa, na primeira metade do século XIX, a Coroa Portuguesa sentiu-se obrigada a instituir nova política oficial de defesa e proteção do Território. Era temido que forças Napoleônicas dominassem o império português, então sediado no Rio de janeiro. Após o Grito do Ipiranga (guerra da Independência 1822-24), havia também o receio de que as tropas portuguesas que se mantinham leais à Coroa Lusitana (sobretudo no norte do país) pudessem adentrar no interior do Brasil pelos principais rios e prejudicar a independência brasileira.

O Príncipe D. João VI, em 1809, então intensificou a política de defesa em todo o Brasil, viabilizando a construção de presídios militares às margens dos principais rios Brasileiro. Considerando o rio como uma estrada fluida natural, por si só, constitui uma via de entrada para o sertão. A fundação de Presídios às margens dos principais rios brasileiros seria uma das garantias contra possíveis invasões.

Nesse período, o Rio Araguaia era visto como um canal aberto a qualquer tipo de invasão, razão das várias tentativas de se implantar colônias militares às suas margens. Não havia vilarejos, vilas ou cidades. Neste cenário de paisagem in natura, todas as margens do rio Araguaia eram habitadas tão somente, por grupos indígenas de várias etnias: Xavantes, Karajás, Javaés e outros. Eram avessos à aplicação desta política e tentaram impedir, de todas as formas, a entrada do colonizador, principalmente os das tribos dos Caiapós, Karajás e Xavantes.

Já na segunda metade do século XIX, os rios passam a ser vistos, principalmente no discurso dos Presidentes da província, como uma nova fronteira a ser conquistada e ocupada sistematicamente, para possibilitar uma ligação com o litoral, uma saída em duplo sentido, como caminho e como meio de salvar a Província do marasmo em que se encontrava (Viana, 1974, p.60).

Com o fechamento da navegação do Rio Paraguai durante o conflito (guerra do Paraguai, 1864-70), a situação da Província de Goiás ficou ainda mais difícil, tanto no fornecimento de mercadorias, como na locomoção de pessoas e no abastecimento militar. José Vieira de Couto Magalhães, ao assumir a Presidência da Província do Mato Grosso, em 02 fevereiro de 1867, em plena guerra, planejou e promoveu a integração entre Mato Grosso e Pará através da navegação pelo Araguaia. Nesse contexto, nasce o Presídio de Itacaiú, em 18 de fevereiro de 1867, com a pretensão de atender as necessidades vigentes. Assim, aos 28 dias do mês de maio de 1868 inaugura-se a navegação a vapor do Rio Araguaia, com a presença de autoridades da Província de Mato Grosso e de Goiás ${ }^{1}$.

\footnotetext{
${ }^{1}$ Acta da Inauguração da navegação A Vapor do Rio Araguaia. CX. Municípios Diversos - Presídio de S. Leopoldina - 1859. Fundação Cultural Pedro Teixeira/ Diretoria de Patrimônio Histórico e Artístico Arquivo Histórico Estadual de Goiás.
} 
Foi um período em que o governo Imperial deu andamento à conquista de novos espaços territoriais em vários rios das bacias hidrográficas brasileiras. Fase Nacional do Desenvolvimento da Navegação a vapor. Os rios brasileiros passam a serem vistos como o caminho mais indicado para o desenvolvimento do comércio e integração com as vastas regiões do Brasil.

Assim sendo, os presídios serviriam de portos de embarque e entrepostos comerciais, sem perder a função de defesa territorial. A continuidade de implantação de presídios visava a fomentar o comércio e com isso, incentivava-se a conquista e ocupação da região.

Nessa conjuntura, a navegação fluvial brasileira apresenta-se como meio de propiciar condições de vida fundamentada no intercâmbio mais efetivo com o exterior. Havia a urgente necessidade de aproveitamento dos principais rios brasileiros, como meios de transporte e como forma de povoar suas margens.

O governo Imperial mostrou interesse no melhoramento das vias navegáveis do Brasil Império com a pretensão de estabelecer comunicação comercial do centro do Brasil com o litoral.

Os governantes optaram pela via fluvial como um meio mais viável de comunicação, devido à falta de estradas, fator que dificultava o acesso dos comerciantes aos centros consumidores. A ligação com os portos marítimos promoveria o escoamento da produção destinada à Metrópole portuguesa.

A Província de Goiás enfrentava uma grande crise econômica, por longo período e os dois grandes rios - Araguaia e Tocantins - passam a ser considerados os escoadores naturais do sertão goiano. A solução seria a implantação da Navegação a Vapor. Era preciso desenvolver o comércio e a navegação a Vapor do Araguaia.

Portanto, para se tornar possível o trânsito dos viajantes, era preciso cogitar, antes de tudo, a fixação de núcleos de povoamento. A criação de presídios garantiria a defesa e o escoamento da produção e, serviria, também, de pernoite aos viajantes, facilitando as comunicações entre Províncias, o desenvolvimento da região e, conseqüentemente, beneficiando a metrópole portuguesa.

Conquistar espaços ocupados pelos índios favorecendo o estabelecimento de pequenos núcleos de povoamento; defender os colonos ${ }^{2}$, os comerciantes e também os moradores dos conflitos existentes entre colonos e índios, bem como, impedir a entrada de invasores para o interior do Brasil, foram os principais objetivos dos dirigentes portugueses, na colonização do Vale Araguaia.

Os poucos comerciantes da Província de Goiás se sentiam inseguros ao se aventurar a percorrer longos trechos de um povoado a outro, e de Goiás a outra região, em busca de produtos para comercializarem. Haviam muitas barreiras nas rotas fluviais, como por exemplo: a imensa extensão do território, a grande extensão fluvial, bem como distantes e deficientes povoações da região, que ficavam isoladas umas das outras no próprio interior da Província; doenças como malária, provocadas por mosquitos e pernilongos; animais selvagens. Ainda havia a presença acentuada de numerosos povos indígenas de várias etnias, tais como os Xavantes, Karajás, Caiapós, Javaés, Canoeiros que eram resistentes à colonização. A falta de estrada era um fator que dificultava o acesso dos comerciantes aos centros consumidores.

O interior da Província de Goiás era caracterizado como um sertão pouco povoado, com vilarejos dispersos, praticamente sem estradas, sem comércio, sem meios de comunicação. As margens ribeirinha do Araguaia, especificamente, eram caracterizadas como lugares inóspitos, desconhecidos. Era uma região rica de elementos naturais, contudo, sem infra-estrutura e, de modo que, tornava a vida difícil àqueles que se aventuravam a fixarem residência.

O governo imperial, ciente da decadência acentuada da Capitania de Goiás, adotou medidas com o intuito de promover o desenvolvimento da agricultura, da pecuária e da navegação dos rios

\footnotetext{
${ }^{2}$ Os colonos, segundo Celso Furtado (FURTADO, 1982, p.127), eram todos os imigrantes que se dirigiam para os núcleos
} de povoamento, destinados a prestar serviços nas atividades agrícolas, por iniciativa do governo imperial (fazendeiros). 
Araguaia e Tocantins, bem como resolver questões atinentes aos povos indígenas que habitavam as margens do Araguaia, com a criação de aldeamentos que foram estabelecidos ao longo do século XIX. Prevalecia à necessidade de implantação dos presídios, bem como o fortalecimento da política de catequese dos índios, com a implantação de aldeamentos em cada ponto estratégico do Rio Araguaia. Os dirigentes políticos entendiam que a resistência indígena, era um dos grandes obstáculos ao povoamento. A política era aumentar ainda mais a defesa construindo várias colônias militares ao longo do rio Araguaia, paralelamente com a formação de aldeamentos indígenas que deveriam ser dirigidos por missionários.

Nessa lógica, uma boa relação interétnica facilitaria a conquista e expansão das fronteiras. Para dar apoio logístico a navegação, defender os colonos contra as investidas dos índios e proteger o território, Teotônio Segurado, Ouvidor da Comarca do Norte de Goiás, defendia já em 1806, que, as primeiras providências a serem tomadas seriam implantar presídios militares:

Três, ou quatro Feitorias no Araguaya, e duas no Maranhão, juntas com o privilégio de não pagarem Dízimos pelo espaço de 10 annoz as pessoas, que se estabelecerem nas margens dos ditos rios, afiançarão aos navegantes tanto a sua subsistência, como a sua segurança da parte dos Gentios (Segurado, 1806).

Evidenciam-se ainda nos escritos de Teotônio Segurado uma série de objetivos na política de expansão da fronteira: demográfico - através da expansão do povoamento nas margens dos principais rios de comunicação, veria a prosperidade do comércio; morais - pretendiam-se transferir os marginalizados para as colônias militares e dar a eles trabalhos; militar - defender o território; e, naturalmente econômico - viabilizaria o desenvolvimento do comércio interno e externo. Teotônio estava convicto de que era possível fazer prosperar esta parte do Brasil.

Segurado defendia a idéia da criação de uma sociedade mercantil, empreendimento necessário para assegurar as condições de comercialização dos produtos nativos e produzidos por essa Capitania com a Capitania do Pará. Fazia-se necessário fundar estabelecimentos comerciais ou entrepostos comerciais, fortificados, para que os colonos pudessem negociar com os povos residentes às margens do rio os produtos que deveriam ser transportados. Era preciso dar isenção do dízimo de tudo que o comerciante produzia, pelo espaço de dez anos aos moradores dos presídios, bem como dar privilégio de pagar somente a metade dos 'direitos da entrada' por dez anos aos cidadãos que fizessem o comércio com o Pará. Esse direito era mais um imposto instituído na época.

Teotônio Segurado priorizou o comércio da região norte da Capitania de Goiás com a Praça de Belém do Pará. Estava convicto de que o desenvolvimento da Província passava, impreterivelmente, pelo incentivo do comércio com o Pará, pela via fluvial. Rosa Cavalcante afirma que:

Teotônio Segurado privilegiou a utilização da via de comunicação natural entre essas regiões - a fluvial - em detrimento da rota terrestre que ligava a Capitania à Bahia, Minas Gerais e São Paulo, uma vez que esta prejudicava o comércio regional pelo elevado custo dos produtos importados (Cavalcante, 1999, p. 55).

A década de 1870 é um referendo importante para o desenvolvimento do comércio e, da instalação dos presídios do Araguaia, que serviram de portos de embarque e entreposto comercial na rota que liga Leopoldina a Patos no Pará, "garantindo o reabastecimento dos barcos de carreira e o apoio às pequenas embarcações" (Tiballi, 1991, p. 33).

\section{Considerações Finais}

Após a instalação da Companhia, verificou-se um incremento em todos os setores da vida dos povoados ribeirinhos. Em face disto, o contato dos moradores dos presídios com os viajantes, que por ali passavam e se hospedavam, tornou-se mais acentuado.

A implantação da companhia foi um elo propulsor do aumento do fluxo migratório e do desenvolvimento econômico dos presídios militares. Além desta via, as populações dos Presídios, já se 
comunicavam com outros povoados, por trieiros ${ }^{3}$. Viajavam montados em animais eqüinos. 0 Presídio de Santa Maria se comunicava via terrestre com Pedro Afonso e Porto Imperial (Porto Nacional), cidades localizadas à margem esquerda do rio Tocantins. O Presídio de Santa Leopoldina se comunicava com a capital da Província, a cidade de Goiás.

Nos presídios Militares de Itacayú, Santa Leopoldina, Santa Maria e São João do Araguaia se faziam o embarque e desembarque de passageiros e de mercadorias. As linhas de navegação a vapor partiam uma para o sul, saindo de Santa Maria até a pequena povoação de Mato Grosso, denominada Itacayú, outra partia para o norte, saindo de Itacayú até o Presídio de Santa Maria.

De Santa Maria os navegantes seguiam viagem em botes menores, com destino a Belém do Pará. Os navegantes que saíam de Leopoldina com destino a Belém levavam mais ou menos seis meses para fazer esse percurso. Fruto desse empreendedorismo, o sistema de circulação de informações deixou de ser tão precário. Os viajantes que por ali passavam traziam notícias dos acontecimentos do Brasil Império.

Com a estabilização da navegação, a comunicação melhorou em vista da implantação dos Correios, ainda que as informações fossem periódicas e chegassem com bastante atraso, a empresa era obrigada a transportar as malas do correio conforme definida na cláusula IX do Decreto de $\mathrm{n}$ o 4.593 de 9 de setembro de 1870. Nos pontos onde havia agências, os comandantes mandavam receber e entregar em terra, as malas e, onde não havia, o diretor geral dos correios providenciava para que a entrega e recebimento fosse feita a bordo dos vapores.

Doles (1973, p.131) afirma que "a ligação do Araguaia e alto Tocantins representou um dos elementos importantes da rede de viação a vapor do Império, qualquer que fosse o plano geral definitivo". O Dr. Couto de Magalhães, após seis anos de árduo trabalho em defesa do desenvolvimento comercial via Araguaia foi acusado de utópico e louco. Segundo Doles, Couto assim respondeu a essas acusações:

[...] havia empreendido e agora digam o que disserem, nem por isso deixará de ser certo que dei o primeiro passo e mais considerável passo para unir a foz da Amazônia à do rio da Prata pelo nosso interior: essa Glória ninguém pode me tirar (Doles, 1973, p. 131).

O comércio fluvial influenciou positivamente a vida dos moradores dos povoados de Itacayú, Chambioás, Santa Rita, São José dos Martírios (fundados posteriormente), Leopoldina e Santa Maria. Os sistemas culturais diferentes se interrelacionaram e interagiram com o desenvolvimento da navegação. Embora lenta, após dez anos de instalação da navegação a vapor no Araguaia, o comércio se firmava. Em 1879, o volume da exportação (20.300 quilos) ainda apresentava-se inferior ao das exportações (38.200 quilos), mas permitia ao sul, na década de 1870, participação mais ativa nas vantagens do comércio com o litoral norte (Doles, 1973, p. 119).

As políticas de povoamento, catequese e navegação podem não ter atingido os objetivos esperados, mas alteraram a paisagem ribeirinha. A navegação provocou mudanças nas estruturas sociais entre comunidades. Abriu um novo espaço para as relações humanas e comerciais do sertão do Araguaia, cujas tradições e crenças de um povo vindo de todas as províncias do Brasil, se fundiram.

O processo de ocupação e apropriação da região do médio Araguaia avançou com dificuldades, no século XIX, devido aos vários entraves acima relatados. Contudo, apesar da lentidão deste processo, essas ações representaram passos fundamentais no processo de conquista de um território igualmente cobiçado por povos indígenas e não-índios.

Os presídios fundados às margens do Rio Araguaia produziram o efeito de conquista e ocupação. Evidentemente, não ocorreram sem o sacrifício de muitas vidas e o custo de relações entre povos indígenas e não índias extremamente assimétricas, ou seja, em que os povos indígenas ou foram dizimados, ou abandonaram o território para os conquistadores.

\footnotetext{
${ }^{3}$ Trieiros : Pequenas e estreitas estradas feitas para só uma pessoa ou animal passar.
} 
Esses presídios trouxeram pelo menos duas grandes conseqüência para o processo de conquista e apropriação do território: a primeira reside na apropriação e expansão de fronteiras e a segunda, a dizimação e expulsão de grupos indígenas daquela parte do Brasil.

A navegação do Araguaia pode ser considerada um fator socioeconômico dinamizador, fundamental nos processos de integração cultural dos povos ribeirinhos entre o de dentro e o de fora, visto que, promoveu um processo de constante convívio social entre povos de culturas antagônicas. As práticas culturais tornaram-se híbridas, tais como os hábitos e crendices alimentares. A hibridez cultural ocorreu através dos limites simbólicos.

As populações ribeirinhas do Araguaia, do século XIX, tentaram vencer as hostilidades do dia-adia com uma inventividade em que se revelam como heróis anônimos. Conseguiram transmitir muitos de seus singulares costumes culturais herdados através dos contatos e intercâmbios entre povos de culturas distintas. Tal postura contribuiu para que expressões lingüísticas, saberes e crenças populares, pudessem transpor as barreiras do tempo e sobreviverem ao longo do século XX.
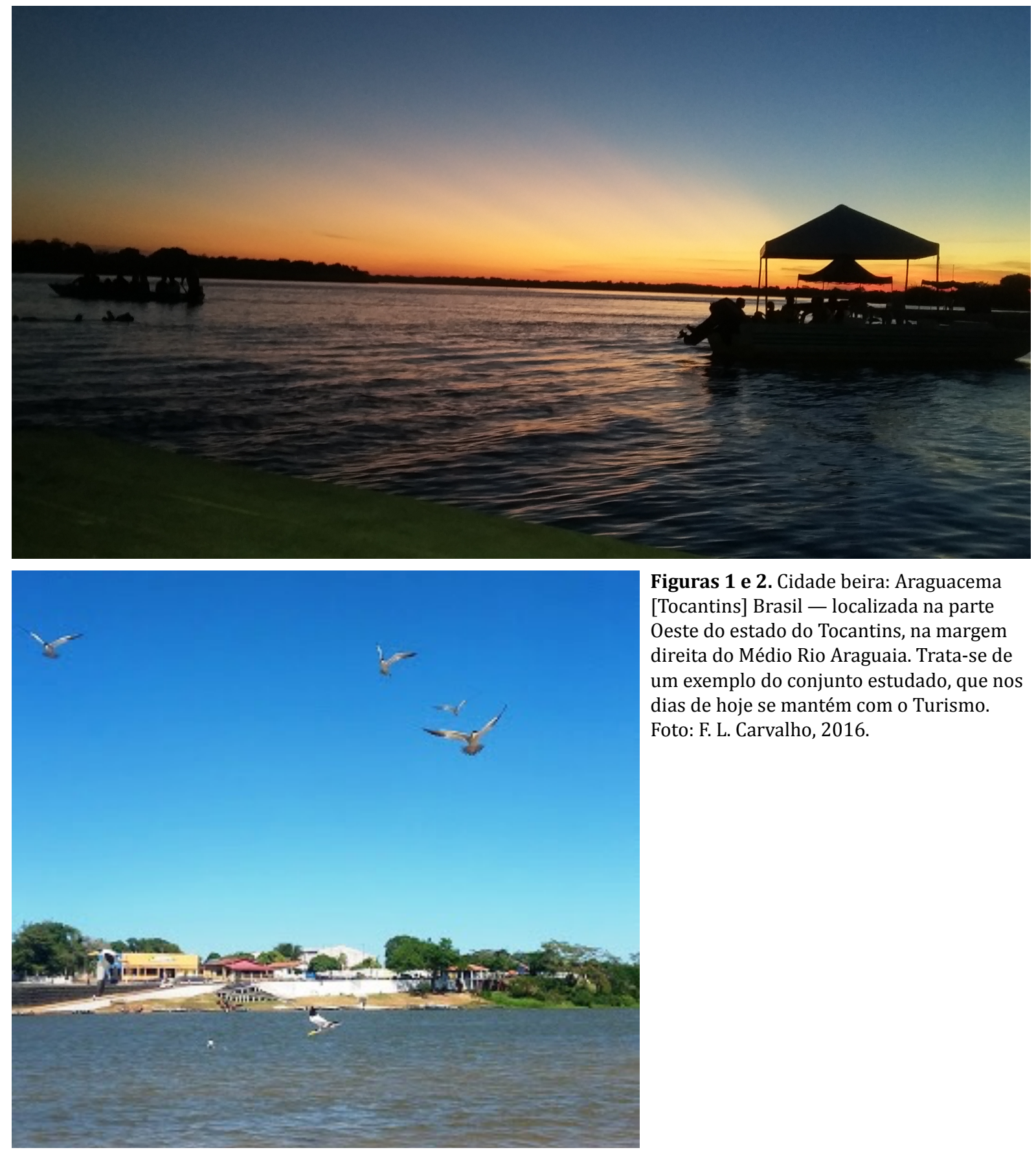

Figuras 1 e 2. Cidade beira: Araguacema [Tocantins] Brasil — localizada na parte Oeste do estado do Tocantins, na margem direita do Médio Rio Araguaia. Trata-se de um exemplo do conjunto estudado, que nos dias de hoje se mantém com o Turismo. Foto: F. L. Carvalho, 2016. 


\section{Referências}

Carvalho, F. L. (2006). Fronteiras e Conquistas pelo Araguaia (132 p. il.). Goiânia: Kelps.

Carvalho, F. L. (2009). Nas águas do Araguaia - a navegação e a hibridez cultural - século XIX (176 p.il.). Goiânia: Kelps.

Cavalcante, M. do E. S. R. (1999). Tocantins - O movimento Separatista do norte de Goiás 1821-1988. São Paulo: A. Garibaldi, Editora da UCG.

Doles, D. E. M. (1973). As Comunicações Fluviais pelo Tocantins e Araguaia no século XIX. Goiânia: Ed. Oriente.

Furtado, C. (1982). Formação Econômica do Brasil (18a. ed.) São Paulo: Editora Nacional.

Gandara, G. S. (2005). Rio Parnaíba: Velho Monge entre a história e a Imagem. Revista Fragmentos de Cultura, 1(1), 179-196. Goiânia: UCG.

Goias (1859). Acta da Inauguração da navegação A Vapor do Rio Araguaia. CX. Municípios Diversos - Presídio de S. Leopoldina. Fundação Cultural Pedro Teixeira. Diretoria de Patrimônio Histórico e Artístico Arquivo Histórico Estadual de Goiás.

Goias. Arquivo Histórico de Goiás (1870). Jornal da Província de Goyaz, anno II, no 45 de 11 de novembro de 1870, folhas 4 e 6. Goiânia [GO].

Mello, J. dos S. (2000). Terra Braba. Goiãnia: Kelps.

Palacin, L., \& Moraes, M. A. S. (1989). História de Goiás (1722-1972) (5a. ed.). Goiânia: Ed. UCG.

Prado Jr., C. (1996). História Econômica do Brasil (40a. ed.). São Paulo: Editora Brasiliense.

Segurado, J. T. (1982). Memória Econômica e Política sobre o Comércio Ativo da Capitania de Goiás (1806). Memórias Goianas I. Originalmente publicado em 1806.

Tiballi, E. F. A. (1991). A expansão do povoamento em Goiás - Século XIX. Dissertação de Mestrado [História das Sociedades Agrárias], Universidade Federal de Goiás, Goiânia, GO, Brasil.

Vianna, O. F. J. (1974). Instituições Políticas Brasileiras (Vol. I, 3a. ed.). Rio de. Janeiro: Record Cultural. 